\title{
Complications of laser prostatectomy: a review of recent data
}

\author{
Malte Rieken • Nicole Ebinger Mundorff • \\ Gernot Bonkat $\cdot$ Stephen Wyler $\cdot$ Alexander Bachmann
}

Received: 28 July 2009/Accepted: 24 December 2009/Published online: 6 January 2010

(C) Springer-Verlag 2010

\begin{abstract}
Introduction Laser techniques for the treatment of bladder outlet obstruction (BOO) due to benign prostate enlargement (BPE) have emerged as an alternative to transurethral resection of the prostate (TURP) and open prostatectomy (OP).

Materials and methods A Medline search over the past 4 years was performed to assess the safety, intra- and postoperative morbidity of various laser techniques.

Results Data on holmium laser enucleation of the prostate (HoLEP) show the highest grade of evidence with two meta-analyses available and prove the low intra- and postoperative morbidity with reproducible long-term results. Photoselective vaporization of the prostate (PVP) with the Greenlightlaser (potassium titanyl phosphate, KTP or lithium borate, LBO) is characterized by excellent haemostatic properties in patients with or without oral anticoagulation. Long-term results show a reoperation rate comparable with TURP; however, there is a lack of randomized trials. Various types of diode lasers with different wavelengths are available for laser vaporization; despite their favourable haemostatic properties, a higher invasion depth seems to result in necrosis of the tissue leading to a higher rate of reoperation. Thulium-laser resection of the prostate shows promising intra- and postoperative morbidity, but data are limited and initial results need to be confirmed in large-scale trials.

Conclusion In summary, HoLEP- and KTP-, or LBOlaser vaporization of the prostate are the most mature
\end{abstract}

M. Rieken $(\bowtie) \cdot$ N. Ebinger Mundorff · G. Bonkat ·

S. Wyler · A. Bachmann

Department of Urology, University Hospital Basel,

Spitalstrasse 21, 4031 Basel, Switzerland

e-mail: mrieken@uhbs.ch techniques of laser prostatectomy and treatment alternatives to TURP and OP, whereas the clinical value and durability of procedures with diode laser systems and the thulium laser need to be confirmed in high-quality prospective RCTs.

Keywords Laser prostatectomy .

Benign prostate hyperplasia $\cdot$ Complications

\section{Introduction}

Lower urinary tract symptoms (LUTS) due to benign prostate enlargement (BPE) is a highly prevalent disease. Nearly $60 \%$ of the cohort of the Baltimore Longitudinal Study of Aging had some degree of clinical BPH by the age of 60 years [1]. The most common indication for surgery is LUTS refractory to medical treatment [2]; other indications include recurrent urinary tract infections, recurrent haematuria, renal insufficiency due to obstruction or bladder stones [2].

Transurethral resection of the prostate (TURP) is the gold standard in men with prostates from 30 to $80 \mathrm{ml}$ [2], while open prostatectomy $(\mathrm{OP})$ is the regarded the treatment of choice in larger sized prostates. TURP can be associated with complications like bleeding or the absorption of irrigation fluid (TUR syndrome), which may have severe consequences like cerebral or bronchial oedema [3-5]. OP leads to substantial and long-lasting improvement of voiding parameters and micturition symptoms; however, it is associated with notable perioperative morbidity, a relatively long hospitalization and limited eligibility for high-risk patients [6-8].

With an ageing population and consecutive increasing morbidity of urological patients, there is a need for 
minimal-invasive treatment alternatives. In recent years, various laser techniques have been developed to overcome complications of TURP and OP while striving to achieve comparable functional results. Currently, data on HoLEP and to a minor extent on PVP with the KTP- or LBO-laser offer a high grade of scientific evidence that these therapeutic modalities are recommendable alternatives to TURP and PVP. Thuliumlaser ablation and diode laser vaporization of the prostate are challenging results of HoLEP or PVP, but further trials are needed to evaluate their clinical value.

This review focuses on the rate of intra-, perioperative and long-term complications of each approach alone or in comparison to TURP or OP to further elucidate their potential advantages and limitations.

\section{Methods}

The data collection is based on a MEDLINE search over the past 4 years that focused on publications in English language on HoLEP, PVP with the KTP- or LBO-laser, thulium-laser prostatectomy and diode-laser prostatectomy. Levels of evidence were rated according to the latest version of the level-of-evidence rating system [9].

\section{Results}

Holmium laser enucleation of the prostate

\section{General aspects}

The holmium:yttrium-aluminium-garnet (Ho:YAG) laser is a solid-state pulsed laser. The light produced has a wavelength of 2,100-2,150 $\mathrm{nm}$ and is rapidly absorbed by water and cell fluid. The penetration depth in prostatic tissue is $0.4 \mathrm{~mm}$; the resulting high-energy density creates vaporization without a deep coagulation zone. The prostatic tissue can be precisely incised, dissected and enucleated. With the introduction of a mechanical tissue morcellator, a rapid development of the enucleation technique was initiated which has proven to be superior over the nowadays largely abandoned holmium laser ablation of the prostate (HoLAP) and holmium laser resection of the prostate (HoLRP) [10, 11].

\section{Intraoperative complications}

Several studies have proven the safety and low intraoperative morbidity of HoLEP. In an extensive review of literature published between 2003 and 2006 including a total of 1,847 patients Kuntz [10] reports a low rate of blood transfusion (1\%) and perioperative mortality $(0.05 \%)$. Another review shows capsular perforation ranging from 0.3 to $10 \%$ which were usually small capsular lacerations and did not change the subsequent management of patients. Bladder injury is reported from 0.5 to $18.2 \%$ with superficial mucosal injury solely requiring bladder irrigation in most of the cases. Superficial ureteric orifice injury not requiring insertion of a ureteral stent or nephrostomy ranges from 1.0 to $2.1 \%$, incomplete morcellation ranges from 1.9 to $3.7 \%$ of all cases, and cardiac events were reported in up to $1.2 \%$ of patients undergoing surgery [12]. Analysis of the occurrence of complications reveals a correlation with grade of experience of the surgeon [13, 14]. In trained hands, prostate size had no statistically significant influence on intraoperative complications [15]. Capsular perforations are more likely to occur in smaller prostates, while injury of the ureteric orifice mainly occurs while resecting large and endovesically growing median lobes $[12,13]$. Compared with TURP and OP, patients undergoing HoLEP have a shorter catheterization time, hospital stay, less blood loss and fewer blood transfusions at comparable functional outcome [16-20].

\section{Early postoperative complications}

Complications within the first months after HoLEP have been reported in numerous trials. Haemorrhage needing coagulation is reported in $0-6 \%$ and clot retention in $0-3 \%$ [12]. The reported reoperation rate was $2.9 \%$ in a level $1 \mathrm{a}$ metaanalysis and is reported in up to $12 \%$ in a level $1 \mathrm{~b}$ randomized clinical trial $[10,12]$. Postoperative dysuria, defined as burning and transient urge-incontinence occur frequently after HoLEP, TURP and OP. In a level $1 \mathrm{~b}$ prospective randomized trial comparing HoLEP and OP for patients with prostates larger than $70 \mathrm{~g}$, at 3-month followup transitory urge-incontinence was equally observed in $34.1 \%$ (HoLEP) and $38.6 \%$ (OP) of the cases, whereas dysuria was significantly more frequent in the HoLEP group (68.2 vs. $41.0 \%, p<0.001)$ [17]. A multicenter, prospective, randomized study comparing HoLEP and TURP showed no significant difference in the reported rate of transitory urge-incontinence, whereas dysuria occurred significantly more often in patients after HoLEP (58.9 vs. $29.5 \%, p=0.0002$ ) [21]. Early postoperative stress incontinence occurs as a rare event after HoLEP and is reported in around $2 \%$ of the cases and comparable with results from TURP and OP [20, 21].

\section{Late complications}

In recent years, numerous trials with long-term outcome of HoLEP were published and have confirmed the longlasting and significant improvement of voiding at a low 
complication rate. In an analysis of 38 patients with a follow-up of 6 years, Gilling et al. report occurrence of urge-incontinence in three patients, mixed incontinence in four patients and stress incontinence in one patient. Reoperation (HoLEP) was necessary in one patient $(1.4 \%)$ after 5 years and one patient $(1.4 \%)$ underwent urethrotomy at 6 months [22]. Comparable long-term results were reported from other studies with a reoperation rate of $4.2 \%$ due to $\mathrm{BPH}$, urethral strictures $(1.7 \%)$, meatal stenosis $(0.8 \%)$ and bladder neck contracture $(0.8 \%)$, resulting in a 5-year surgical retreatment-free rate of $92 \%$ according to KaplanMeier plot. A comparison of the learning curve showed a higher retreatment rate in the earlier group of patients $(8 \mathrm{vs}$. $1.4 \%$ ) [23]. Vavassori et al. [24] observed a reoperation rate of $2.7 \%$ during 36-month follow-up; incidence of urethral stenosis and bladder neck contracture was significantly higher in the group of patients with prostates smaller $50 \mathrm{~g}$. Long-term results and complications of HoLEP in comparison with TURP and OP have been reported in recent years. Reoperation rates in a level $1 \mathrm{~b}$ prospective, randomized trial were comparable at 3-year follow-up with a rate of 7.2 and $6.6 \%$ for HoLEP and TURP, respectively [20]. These data are confirmed by other prospective trials comparing HoLEP to TURP [16]. The long-term safety of HoLEP for procedures performed in large prostates is confirmed by prospective, randomized trials comparing HoLEP to OP. Kuntz et al. observed a reoperation rate at 5-year follow-up of 5 and $6.7 \%$ for HoLEP and OP, respectively [19]. Comparable results are reported from the 24-month follow-up from Naspro et al. [17].

Data on the impact of HoLEP on sexual function are scarce. It has been previously shown that both HoLEP and TURP significantly lowered the IIEF orgasmic function domain due to retrograde ejaculation, while no difference in overall erectile function was observed [25]. Similar results were shown in the comparison of HoLEP and OP, with no significant reduction of erectile function as compared with the baseline preoperative value [17]. Retrograde ejaculation was reported in 75 and $62 \%$ of patients undergoing HoLEP and TURP, respectively [16].

Photoselective vaporization of the prostate

\section{General aspects}

In the early 1990s, visual laser ablation of the prostate with the $1,064 \mathrm{~nm}$ neodymium:yttrium-aluminium-garnet (Nd:YAG) laser was introduced [26]. The low-absorption coefficient in most tissues with a penetration depth of 4 and $18 \mathrm{~mm}$ resulted in low energy leading to a deep coagulative necrosis of the tissue [10]. Despite intraoperative safety, improvement of symptoms and voiding parameters was inferior to TURP, and the rate of reoperations was considerably higher, so that VLAP has been abandoned [27, 28]. Passing the Nd:YAG-produced beam (1,046 nm) through a KTP or LBO crystal, which doubles the frequency and thus halves its wavelength, leads to a green visible light beam of $532 \mathrm{~nm}$, which has a completely different laser beam-tissue interaction. The wavelength is not absorbed by water but strongly absorbed by haemoglobin, resulting in enhanced haemostatic properties. The absorption length in vascularized tissue as the prostate is only $1-3 \mathrm{~mm}$ and the high-energy density leads to a rapid and efficient vaporization of the tissue [29, 30].

Most of the trials published until 2008 are based on the 80-W KTP laser, whereas only limited data are available on the higher-powered 120-W LBO laser.

\section{Intraoperative complications}

Several studies have proven the high intraoperative safety of photoselective vaporization of the prostate (PVP) alone [31-33] or in comparison to TURP [34-37] or OP [38] and in subgroups of patients with large prostates [39, 40], on anticoagulation [40, 41] or in retention [40, 42]. A level 4 analysis of 500 patients undergoing 80-W KTP PVP reported intraoperative bleeding in $3.6 \%$, capsule perforation in $0.2 \%$ and conversion to TURP due to bleeding, prostate size or fibre defect in $5.2 \%$ of the patients. No TUR syndrome was observed and no blood transfusions were necessary [31]. The high intraoperative safety could be confirmed for the 120-W LBO-laser with an intraoperative bleeding rate of $1-2.6 \%$, capsule perforation in $1 \%$, intraoperative blood transfusion in $0.4 \%$ and no TUR syndrome reported $[32,33]$. The analysis of intraoperative complication of patients on anticoagulation, on retention or with large prostates larger than $80-100 \mathrm{ml}$ showed no significant difference to the average population of patients [39-42]. Comparative level 3b studies showed a significantly higher rate of transfusion with TURP; the findings regarding the rate of bleeding are inconsistent with but in favour of PVP [34-37]. The only currently available level 1 b prospective, randomized trial comparing 80-W PVP with OP for prostates greater than $80 \mathrm{ml}$ showed a significantly higher rate of perioperative blood transfusions in the OP group [38].

\section{Early postoperative complications}

The rate of early postoperative complications has been documented in all studies mentioned above [31-36, 3842]. Haematuria was reported in $9.8 \%$, blood transfusion in $0.4 \%$, revision in $0.6 \%$ acute renal failure in $0.6 \%$, urosepsis in $0.4 \%$ dysuria in $14.8 \%$, transient urge-incontinence in $2.4 \%$ and urinary tract infection in $6.8 \%$ after PVP with the KTP-laser in a level 4 case series [31]. The 
findings are comparable with results obtained by other authors [32, 33]. No correlation with the occurrence of early postoperative complications could be found in patients in retention, whereas haematuria was significantly more frequent in patients with anticoagulation (17.2 vs. $5,4 \%, p=0.001$ ) [41] and prostates larger than $80 \mathrm{ml}$ (17.2 vs. $9.8 \%, p<0.05)$ [31]. Patients with prostates smaller than $40 \mathrm{ml}$ had a significantly higher rate of dysuria than the overall study population ( 24.3 vs. $14.8 \%$, $p<0.01$ ) [31]. Comparing PVP to TURP in patients with prostates larger than $70 \mathrm{ml}$, Horasanli et al. observed a higher rate of urinary retention after PVP (15.3 vs. $2.7 \%$, $p=0.02)$ in their level $1 \mathrm{~b}$ trial. This is in contrast to nonrandomized trials in patients with prostates smaller than $70 \mathrm{ml}[35,36]$. A significant higher rate of haematuria with transient bladder irrigation and clot retention was observed after TURP in a non-randomized trial, while the rate of revision, blood transfusion, acute renal failure, dysuria and urinary tract infection were comparable [35]. No difference in the incidence of postoperative complications was documented in the level $1 \mathrm{~b}$ prospective randomized trial comparing PVP to OP for prostatic adenomas greater than $80 \mathrm{ml} \mathrm{[38].}$

\section{Late complications}

One of the major limitations in evaluating the longevity and long-term morbidity of PVP is the current lack of long-term data from level $1 \mathrm{~b}$ randomized trials. The longest follow-up with the highest number of patients was reported by a level 4 case series Hai. Of 246 patients available for analysis at 5year follow-up after PVP, 19 (7.7\%) had to be retreated with PVP due to recurrent adenoma and three (1.2\%) underwent incision of the bladder neck resulting in an overall retreatment rate of $8.9 \%$ [43]. These data are comparable with results from a level 4 case series from our own centre with a retreatment rate of $14.8 \%$ due to recurrent or persisting adenoma tissue $(6.8 \%)$, bladder neck strictures $(3.6 \%)$ or urethral strictures (4.4\%); however, only 27 patients were available at 5-year follow-up [31]. Anticoagulation and urinary retention at the time of surgery have no significant influence on the rate of long-term complications [41, 42]. The efficacy of PVP in patients with larger prostates seems to be reduced. In their level $1 \mathrm{~b}$ prospective randomized trial, Horasanli et al. observed a reoperation rate of $17.9 \%$ within 6-month follow-up after PVP in patients with prostates larger than $70 \mathrm{ml}$ due to persisting tissue, whereas no reintervention was necessary in the TURP group. Furthermore, the functional outcome was superior in the TURP group. In a level $2 \mathrm{~b}$ prospective multicenter study, a decreased efficacy of PVP in patients with larger prostates and PSA levels $\geq 6.1 \mathrm{ng} / \mathrm{ml}$ could be demonstrated [44]. In contrast, level 4 case series showed that the retreatment rate due to recurrent adenoma was not higher in patients with large prostates. However, these studies lack a comparison to TURP or OP $[31,39]$. The rate of bladder neck strictures was significantly higher in patients with prostates smaller $40 \mathrm{ml}(7.8$ vs. $3.6 \%, p<0.05)[31,39]$. Results from nonrandomized trials comparing PVP and TURP show no significant difference in the rate of urethral strictures, bladder neck strictures or reoperation due to recurrent adenoma [35, 36]. The level $1 \mathrm{~b}$ trial comparing OP to $80-\mathrm{W}$ PVP found no difference regarding recatheterization or reoperation at comparable functional outcome; however, longer follow-up needs to be awaited taking into account an observation period of only18 months [38].

Data on sexual function after PVP are limited. Comparing preoperative and 12-month post-operative sexual function in men undergoing PVP, sexual function was maintained in patients who were catheter free or performed intermittent catheterization and improved for patients with indwelling catheters preoperatively [45]. A general improvement of sexual function and erectile function was observed in the 6-month follow-up of another study [46]. The rate of retrograde ejaculation is comparable between TURP and PVP (56.7 vs. $49.9 \%, p=0.21)$ [34], and no difference can be detected between patients undergoing OP and PVP concerning erectile function [38].

\section{Diode-laser prostatectomy}

\section{General aspects}

Various types of diode lasers operating at wavelengths of 940, 980 or $1,470 \mathrm{~nm}$ are available for the application in diode-laser prostatectomy. A preclinical trial performed on the established ex vivo model of the blood-perfused porcine kidney has shown a higher tissue ablation capacity, similar haemostasis and smaller coagulation zone of the 980-nm diode laser compared with the KTP-laser [47]. In contrast, ex vivo studies with a 1,470-nm 50-W diode laser showed a significantly lower capacity of tissue ablation and a significantly larger coagulation zone compared with the $80-\mathrm{W}$ KTP-laser; in an ex vivo setting the mean coagulation zone of a 940-nm diode laser was $4.25 \mathrm{~mm}[48,49]$. Currently, only a few studies investigated the clinical applications and with a maximum follow-up of 1 year. Further studies are essential to further evaluate the technique.

\section{Intraoperative complications}

Currently, clinical data are available on 980 - and 1,470-nm diode-laser [50-52]. All studies, either level $3 \mathrm{~b}$ or 4, show a high intraoperative safety of the diode laser. In a comparison between the safety and efficacy of the 980-nm diode laser and the 120-W Greenlight laser, the rate of 
intraoperative bleeding was significantly lower in the diode-laser group ( 0 vs. $13 \%, p<0.01)$ despite anticoagulation in $51 \%$ of all patients. Furthermore, no capsule perforation was reported, and a conversion to TURP was necessary in $4 \%$ of the cases [50].

\section{Early postoperative complications}

The incidence of early postoperative complications reported in the literature is low; however, the limited amount of data available on the technique has to be taken into account. No postoperative blood transfusions occurred, the rate of dysuria was between 20 and $24 \%$, urinary tract infection was reported in $11 \%$, and the recatheterization rate was up to $20 \%$. [50, 51]. Compared with the $120-\mathrm{W}$ Greenlight laser, the rate of transient urge-incontinence was significantly higher [50].

\section{Late complications}

The rate of late complications reported in the current literature seems to be remarkably high after diode-laser prostatectomy. Within a follow-up of 12 months, reoperation was necessary in $32.1 \%$ of patients after laser-prostatectomy with the 980-nm diode laser due to obstructive necrotic tissue or bladder neck stricture. Furthermore, persisting incontinence occurred in $10.7 \%$ of the patients [53]. After treatment with a 1,470-nm diode laser, re-TURP was necessary in $20 \%$ of patients within 1-year follow-up [51].

\section{Thulium-laser prostatectomy}

\section{General aspects}

The thulium:yrrtium-aluminium-garnet (Tm:YAG) laser operates at a wavelength of $2 \mu \mathrm{m}$ and is delivered as a continuous wave $(\mathrm{CW})$. The wavelength is close to the absorption peak of water and the short penetration depth results in a high-energy density leading to rapid vaporization of the tissue. Ex vivo experiments performed on bloodperfused porcine kidneys showed that the $2-\mu \mathrm{m} \mathrm{CW}$ thulium-laser offers a higher tissue ablation capacity and comparable haemostatic properties with the KTP laser [54]. Two different techniques have been described for the application of the thulium-laser in prostate surgery: enucleation of the prostate [55-57] comparable to HoLEP and vaporesection of the prostate $[58,59]$.

\section{Intraoperative complications}

The rate of intraoperative complications occurring during vaporesection or enucleation with the thulium-laser is low. Intra- or early postoperative bleeding was reported in $3.4 \%$ of the patients undergoing enucleation of the prostate and the rate of blood transfusions was up to $2.2 \%$ [55, 56].Transfusions or occurrence of TUR syndrome are not reported during or after vaporesection of the prostate, whereas in a level $1 \mathrm{~b}$ prospective randomized trial blood transfusion was necessary in $4.2 \%$ with TURP, and TUR syndrome occurred in $2.1 \%$ of the patients $[58,59]$.

\section{Early postoperative complications}

In the early postoperative course after thulium enucleation of the prostate, symptomatic urinary tract infection occurred in $6.8 \%$, a second-look procedure during hospitalization was necessary in $2.2 \%$ and recatheterization occurred in $1.1 \%$ [55]. Comparing the complications of patients with in retention with patients without preoperative indwelling catheter prior to enucleation of the prostate, a significantly higher rate of postoperative haematuria and urinary tract infection was observed in patients in retention [56]. The rate of urinary tract infections after thulium-vaporesection of the prostate ranges from 3.9 to $11.1 \%$. In the current literature, no recatheterization after this intervention is described; transitory urge-incontinence seems to occur less frequently than after TURP (23.1 vs. $31.3 \%, p=0.36)[58,59]$.

\section{Late complications}

In the current literature, data with a follow-up of more than 12 months after thulium-laser prostatectomy are available. Within the follow-up after thulium-laser enucleation, transient recatheterization was necessary in up to $5.6 \%$ of patients, reoperation occurred in $2.8-3.4 \%$ of all patients and voiding symptoms and micturition parameters showed a significant improvement [56, 57]. Within a 1-year followup after thulium-vaporesection of the prostate in 54 men no reoperation was needed in the series of Bach et al. Comparing thulium-vaporesection to TURP, the rate of retrograde ejaculation (55\%), urethral stricture (1.9\%) and stress incontinence (none) shows no significant difference [59]. Despite the encouraging results of this technique, further studies are required to confirm these data.

\section{Discussion}

For several years, TURP and OP have been considered as gold standard in the treatment of BOO due to BPE. Despite their proven clinical outcome, the rate of intraoperative and postoperative morbidity led to the development of alternative surgical methods seeking to produce equal functional results at a lower rate of intra- and postoperative complications. One of the limitations in the analysis of the incidence of complications is that often no classification is 
available or classifications are not used by authors. Several laser types with different wavelengths and consequently different physical properties have been developed in recent years. Tables 1, 2 and 3 summarize complications after various techniques of laser prostatectomy in comparison with landmark publications on TURP and OP, demonstrating especially the high intraoperative safety of laser techniques. However, long-term results from some techniques are scarce, the number of patients in studies often is limited and a remarkably high reoperation rate within a relatively short follow-up is reported from some laser types. Furthermore, underreporting of complications due to loss of follow-up data or insufficient documentation could lead to a bias in clinical studies, making a comparison of various techniques difficult.

The most mature technique for laser prostatectomy is HoLEP. Mimicking OP, the procedure leads to an almost complete removal of tissue leading to a long-lasting improvement of symptoms and micturition parameters. Several trials have proven the intraoperative safety of the technique, showing that patients undergoing HoLEP have a shorter catheterization time, hospital stay, less blood loss and fewer blood transfusions than patients with TURP or OP. During early postoperative follow-up, dysuria is reported more frequently after HoLEP than after OP or TURP. It has to be taken into consideration that these symptoms are primarily self-limiting, rarely requiring medical treatment. Furthermore, definitions of dysuria are often imprecise, ranging from simple burning to alguria. Long-term complications of HoLEP are low and comparable with TURP or OP, supporting the maturity of HoLEP as a real therapeutic alternative to the current gold standard.

Despite the excellent intra- and postoperative safety, HoLEP is primarily restricted to a few centres of

Table 1 Comparison of intraoperative complications after various laser prostatectomies to TURP and OP in recent series

\begin{tabular}{|c|c|c|c|c|c|c|c|}
\hline \multirow[t]{2}{*}{ Author } & \multirow[t]{2}{*}{ Year } & \multirow[t]{2}{*}{ Ref. no. } & \multirow{2}{*}{$\begin{array}{l}\text { No. of } \\
\text { patients }\end{array}$} & \multirow{2}{*}{$\begin{array}{l}\text { Follow-up } \\
\text { (month) }\end{array}$} & \multicolumn{3}{|c|}{ Intraoperative complications (\%) } \\
\hline & & & & & $\begin{array}{l}\text { Blood } \\
\text { transfusion }\end{array}$ & $\begin{array}{l}\text { Capsular } \\
\text { perforation }\end{array}$ & $\begin{array}{l}\text { Bladder/ureteric } \\
\text { orifice injury }\end{array}$ \\
\hline \multicolumn{8}{|l|}{ HoLEP } \\
\hline Montorsi & 2008 & {$[21]$} & 52 & 12 & 0 & - & 18.2 \\
\hline Naspro & 2006 & {$[17]$} & 41 & 24 & 4.0 & - & 7.3 \\
\hline Placer & 2009 & {$[13]$} & 125 & 24 & 0.8 & 10.4 & 4.0 \\
\hline Shah & 2007 & {$[12]$} & 280 & 24 & 0.35 & 9.6 & 6.0 \\
\hline Vavassori & 2008 & {$[24]$} & 330 & 36 & - & - & 5.7 \\
\hline Wilson & 2006 & {$[16]$} & 30 & 24 & 0 & - & - \\
\hline \multicolumn{8}{|l|}{ PVP } \\
\hline Bouchier-Hayes & 2006 & {$[37]$} & 76 & 12 & 0 & - & - \\
\hline Choi & 2008 & {$[33]$} & 305 & 6 & 0.4 & 1.0 & - \\
\hline Horasanli & 2008 & {$[34]$} & 39 & 6 & 0 & 0 & - \\
\hline Rajbabu & 2007 & [39] & 54 & 24 & - & - & 1.8 \\
\hline Ruszat & 2008 & {$[31]$} & 500 & 60 & 0 & 0.2 & - \\
\hline Ruszat & 2008 & {$[35]$} & 269 & 24 & 0 & 0.4 & - \\
\hline Skolarios & 2008 & {$[38]$} & 65 & 18 & 0 & - & - \\
\hline Spaliviero & 2009 & {$[32]$} & 70 & 12 & 0 & 0 & 0 \\
\hline \multicolumn{8}{|l|}{ Diode laser vaporization } \\
\hline Rieken & 2009 & {$[60]$} & 56 & 12 & 0 & 0 & 0 \\
\hline Seitz & 2007 & {$[51]$} & 10 & 12 & 0 & 0 & 0 \\
\hline \multicolumn{8}{|c|}{ Thulium-laser vaporesection/laser enucleation } \\
\hline Bach & 2007 & {$[58]$} & 54 & 12 & 0 & - & - \\
\hline Bach & 2009 & {$[56]$} & 208 & 1 & 0.9 & - & - \\
\hline Xia & 2008 & {$[59]$} & 52 & 12 & 0 & - & - \\
\hline Median laser techniques & & & 65 & 12 & 0 & 0.2 & 4.0 \\
\hline \multicolumn{8}{|l|}{ TURP } \\
\hline Reich & 2008 & {$[60]$} & 10,654 & $<1$ & 2.9 & - & - \\
\hline \multicolumn{8}{|l|}{$\mathrm{OP}$} \\
\hline Gratzke & 2007 & [61] & 902 & $<1$ & 7.5 & - & - \\
\hline
\end{tabular}


Table 2 Comparison of early postoperative complications after various laser prostatectomies in recent series

\begin{tabular}{|c|c|c|c|c|c|c|c|}
\hline \multirow[t]{2}{*}{ Author } & \multirow[t]{2}{*}{ Year } & \multirow[t]{2}{*}{ Ref. no. } & \multirow{2}{*}{$\begin{array}{l}\text { No. of } \\
\text { patients }\end{array}$} & \multirow{2}{*}{$\begin{array}{l}\text { Follow-up } \\
\text { (months) }\end{array}$} & \multicolumn{3}{|c|}{ Early postoperative complications (\%) } \\
\hline & & & & & $\begin{array}{l}\text { Transitory urge/ } \\
\text { storage symtoms }\end{array}$ & Dysuria & Recatheterization \\
\hline \multicolumn{8}{|l|}{ HoLEP } \\
\hline Montorsi & 2008 & {$[21]$} & 52 & 12 & 44.0 & 58.9 & - \\
\hline Naspro & 2006 & {$[17]$} & 41 & 24 & 34.1 & 68.2 & - \\
\hline Placer & 2009 & {$[13]$} & 125 & 24 & 19.2 & 2.4 & - \\
\hline Shah & 2007 & {$[12]$} & 280 & 24 & 10.7 & - & 3.9 \\
\hline Vavassori & 2008 & {$[24]$} & 330 & 36 & 28.0 & - & - \\
\hline Wilson & 2006 & {$[16]$} & 30 & 24 & - & - & 17.0 \\
\hline \multicolumn{8}{|l|}{ PVP } \\
\hline Bouchier-Hayes & 2006 & {$[37]$} & 76 & 12 & 10.5 & - & 3.9 \\
\hline Choi & 2008 & {$[33]$} & 305 & 6 & - & 11.8 & 4.6 \\
\hline Horasanli & 2008 & {$[34]$} & 39 & 6 & - & - & 15.3 \\
\hline Rajbabu & 2007 & [39] & 54 & 24 & 5.5 & - & - \\
\hline Ruszat & 2008 & {$[31]$} & 500 & 60 & 2.4 & 14.8 & - \\
\hline Ruszat & 2008 & {$[35]$} & 269 & 24 & - & 13.0 & - \\
\hline Skolarios & 2008 & {$[38]$} & 65 & 18 & - & 7.6 & 10.7 \\
\hline Spaliviero & 2009 & {$[32]$} & 70 & 12 & 8.6 & - & - \\
\hline \multicolumn{8}{|l|}{ Diode laser vaporization } \\
\hline Rieken & 2009 & {$[60]$} & 56 & 12 & 30.3 & - & 19.6 \\
\hline Seitz & 2007 & {$[51]$} & 10 & 12 & - & 20.0 & 20.0 \\
\hline \multicolumn{8}{|c|}{ Thulium-laser vaporesection/laser enucleation } \\
\hline Bach & 2007 & {$[58]$} & 54 & 12 & - & 10.7 & 0 \\
\hline Bach & 2009 & {$[56]$} & 208 & 1 & - & - & 3.8 \\
\hline Xia & 2008 & {$[59]$} & 52 & 12 & 23.1 & - & 0 \\
\hline Median laser techniques & & & 65 & 12 & 19.2 & 13.0 & 4.6 \\
\hline
\end{tabular}

excellence with high expertise. This is supported by data, showing a positive correlation between experience of the surgeon and rate of complications. The steep learning curve and complexity of the technique anticipate are widespread application of the technique.

In contrast to HoLEP, PVP with the KTP- or LBO-laser is a TURP-like technique relatively easy to learn. Enhanced by marketing, the flat learning curve leads to a widespread use of the technique. Due to its specific physical properties, the procedure is performed in an almost blood-less setting, allowing surgery in high-risk patients under anticoagulation and with large prostates. Intraoperative morbidity is low and early postoperative complications comparable to OP or TURP. One of the major limitations in the evaluation of the longevity and long-term morbidity of PVP is the current lack of data, especially long-term results from level $1 \mathrm{~b}$ prospective, randomized trials. Long-term data include only limited patient number, so that a final evaluation of the technique regarding its long-term durability could not be drawn from currently available scientific evidence.

Diode-laser prostatectomy and thulium-laser vaporization or enucleation of the prostate are recently introduced surgical applications of the laser technology. A general limitation is the lack of large-scale prospective randomized trials with these lasers, making a final evaluation impossible. Diode lasers show excellent haemostatic properties superior to PVP in ex vivo experiments as well as in clinical application. However, a relatively high number of transient urge and reoperations is observed after surgery. The reason is presumably a relatively high invasion depth of the laser energy, leading to damage and necrosis in the underlying tissue. Future technological developments of diode lasers need to overcome these limitations in order to produce long-lasting surgical results. The application of the thulium-laser shows encouraging intra- and postoperative complications. The number of studies which have been conducted with this laser type is limited and the follow-up 
Table 3 Comparison of late complications after various laser prostatectomies to TURP and OP in recent series

\begin{tabular}{|c|c|c|c|c|c|c|c|c|}
\hline \multirow[t]{2}{*}{ Author } & \multirow[t]{2}{*}{ Year } & \multirow[t]{2}{*}{ Ref. no. } & \multirow{2}{*}{$\begin{array}{l}\text { No. of } \\
\text { patients }\end{array}$} & \multirow{2}{*}{$\begin{array}{l}\text { Follow-up } \\
\text { (month) }\end{array}$} & \multicolumn{4}{|c|}{ Late complications (\%) } \\
\hline & & & & & $\begin{array}{l}\text { Persisting urge/ } \\
\text { stress incontinence }\end{array}$ & $\begin{array}{l}\text { Urethral } \\
\text { stricture }\end{array}$ & $\begin{array}{l}\text { Bladder neck } \\
\text { contracture }\end{array}$ & $\begin{array}{l}\text { Reoperation for } \\
\text { recurrent tissue }\end{array}$ \\
\hline \multicolumn{9}{|l|}{ HoLEP } \\
\hline Ahyai & 2007 & {$[20]$} & 100 & 36 & - & 4.1 & 3.1 & 1.0 \\
\hline Elzayat & 2007 & {$[23]$} & 118 & 72 & - & 1.7 & 0.8 & 4.2 \\
\hline Gilling & 2008 & {$[22]$} & 38 & 72 & - & 1.4 & 0 & 1.4 \\
\hline Kuntz & 2008 & [19] & 60 & 60 & - & 3.3 & 1.7 & 0 \\
\hline Montorsi & 2008 & {$[21]$} & 52 & 12 & 1.7 & 1.7 & - & - \\
\hline Naspro & 2006 & [17] & 41 & 24 & 5.4 & $\mathrm{a}$ & $7.3^{\mathrm{a}}$ & - \\
\hline Placer & 2009 & {$[13]$} & 125 & 24 & - & 1.6 & 4.0 & 0.8 \\
\hline Shah & 2007 & {$[12]$} & 280 & 24 & 0.7 & 2.1 & 0.4 & 0 \\
\hline Vavassori & 2008 & {$[24]$} & 330 & 36 & 0.6 & 3.0 & 0.6 & 2.7 \\
\hline Wilson & 2006 & {$[16]$} & 30 & 24 & 3.3 & 3.3 & 0 & 0 \\
\hline \multicolumn{9}{|l|}{ PVP } \\
\hline Bouchier-Hayes & 2006 & [37] & 76 & 12 & - & 0 & 0 & 5.6 \\
\hline Hai & 2009 & {$[43]$} & 321 & 60 & - & - & 1.2 & 7.7 \\
\hline Horasanli & 2008 & {$[34]$} & 39 & 6 & - & 5.1 & - & 17.9 \\
\hline Rajbabu & 2007 & [39] & 54 & 24 & - & - & - & 3.7 \\
\hline Ruszat & 2008 & {$[31]$} & 500 & 60 & 1.2 & 4.4 & 3.6 & 6.8 \\
\hline Ruszat & 2008 & {$[35]$} & 269 & 24 & - & 4.5 & 4.5 & 6.7 \\
\hline Skolarios & 2008 & {$[38]$} & 65 & 18 & - & $\mathrm{b}$ & $\mathrm{b}$ & $4.62^{\mathrm{b}}$ \\
\hline Spaliviero & 2009 & {$[32]$} & 70 & 12 & 0 & 0 & 0 & 0 \\
\hline \multicolumn{9}{|l|}{ Diode laser vaporization } \\
\hline Rieken & 2009 & {$[60]$} & 56 & 12 & 10.7 & - & 12.5 & 19.6 \\
\hline Seitz & 2007 & {$[51]$} & 10 & 12 & - & 0 & 0 & 20.0 \\
\hline \multicolumn{9}{|c|}{ Thulium-laser vaporesection/laser enucleation } \\
\hline Bach & 2007 & {$[58]$} & 54 & 12 & - & 0 & 0 & 0 \\
\hline Bach & 2009 & {$[57]$} & 88 & 16.5 & - & 1.1 & 0 & 2.2 \\
\hline Xia & 2008 & {$[59]$} & 52 & 12 & 0 & 1.9 & 0 & 0 \\
\hline Median laser techniques & & & 65 & 24 & 1.2 & 1.8 & 0.6 & 2.7 \\
\hline \multicolumn{9}{|l|}{ TURP } \\
\hline Madersbacher & 2005 & {$[62]$} & 20,671 & 96 & - & c & $7.3^{\mathrm{c}}$ & 7.4 \\
\hline \multicolumn{9}{|l|}{ OP } \\
\hline Madersbacher & 2005 & {$[62]$} & 2,452 & 96 & & $\mathrm{c}$ & $6.1^{\mathrm{c}}$ & 3.4 \\
\hline
\end{tabular}

${ }^{a}$ Bladder neck contractures and urethral strictures after 24-month follow-up

${ }^{\mathrm{b}}$ Reoperation due to urethral stricture, bladder neck contracture and apical resection after 18-month follow-up

${ }^{c}$ Cumulative incidence of a secondary endoscopic intervention (urethrotomy, bladder neck incision) after 96-month follow-up

still is too short to draw further conclusions about the durability of the procedure. However, results available are encouraging, and future trials will define the clinical significance of the technique.

\section{Conclusions}

In recent years, scientific evidence from various studies has proven the intraoperative safety of PVP and HoLEP.
Long-term data confirm the safety and durability of HoLEP, challenging the established gold standard TURP and OP. One major limitation for the spread of HoLEP is the steep learning curve, restricting HoLEP to specific centres. Longterm data from prospective, randomized trials are still necessary to evaluate the longevity of PVP and define its role in the treatment of BPE. Diode-laser and thulium-laser prostatectomy are in an early stage of clinical evaluation. Despite encouraging results, further data from high-quality RCTs are needed to define their therapeutic role. 
Conflict of interest statement All authors except Bachmann declare no conflict of interest. Bachmann has received Honorarium for presentations from AMS, Bayer, Orion Pharma, Olympus, Astra Zeneca.

\section{References}

1. Arrighi HM, Metter EJ, Guess HA, Fozzard JL (1991) Natural history of benign prostatic hyperplasia and risk of prostatectomy. The Baltimore Longitudinal Study of Aging. Urology 38(1 Suppl): 4-8

2. Madersbacher S, Alivizatos G, Nordling J, Sanz CR, Emberton M, de la Rosette JJ (2004) EAU 2004 guidelines on assessment, therapy and follow-up of men with lower urinary tract symptoms suggestive of benign prostatic obstruction (BPH guidelines). Eur Urol 46(5):547-554

3. Rassweiler J, Teber D, Kuntz R, Hofmann R (2006) Complications of transurethral resection of the prostate (TURP)-incidence, management, and prevention. Eur Urol 50(5):969-979

4. Reich O, Gratzke C, Bachmann A, Seitz M, Schlenker B, Hermanek P, Lack N, Stief CG (2008) Urology Section of the Bavarian Working Group for Quality Assurance., Morbidity, mortality and early outcome of transurethral resection of the prostate: a prospective multicenter evaluation of 10,654 patients. J Urol 180(1):246-291

5. Ho HS, Yip SK, Lim KB, Fook S, Foo KT, Cheng CW (2007) A prospective randomized study comparing monopolar and bipolar transurethral resection of prostate using transurethral resection in saline (TURIS) system. Eur Urol 52(2):517-522

6. Gratzke C, Schlenker B, Seitz M, Karl A, Hermanek P, Lack N, Stief CG, Reich O (2007) Complications and early postoperative outcome after open prostatectomy in patients with benign prostatic enlargement: results of a prospective multicenter study. J Urol 177(4):1419-1422

7. Varkarakis I, Kyriakakis Z, Delis A, Protogerou V, Deliveliotis C (2004) Long-term results of open transvesical prostatectomy from a contemporary series of patients. Urology 64(2):306-310

8. Tubaro A, Carter S, Hind A, Vicentini C, Miano L (2001) A prospective study of the safety and efficacy of suprapubic transvesical prostatectomy in patients with benign prostatic hyperplasia. J Urol 166(1):172-176

9. Levels of Evidence. Centre of Evidence Based Medicine Website. http://www.cebm.net/index.aspx?o=1025

10. Kuntz R (2006) Current role of lasers in the treatment of benign prostatic hyperplasia (BPH). Eur Urol 49(6):961-969

11. Naspro R, Bachmann A, Gilling P, Kuntz R, Madersbacher S, Montorsi F, Reich O, Stief C, Vavassori I (2009) A Review of the Recent Evidence (2006-2008) for 532-nm photoselective laser vaporisation and holmium laser enucleation of the prostate. Eur Urol 55(6): 1345-1357

12. Shah HN, Mahajan AP, Hegde SS, Bansal MB (2007) Perioperative complications of holmium laser enucleation of the prostate: experience in the first 280 patients, and a review of literature. BJU Int 100(1):94-101

13. Placer J, Gelabert-Mas A, Vallmanya F, Manresa JM, Menéndez V, Cortadellas R, Arango O (2009) Holmium laser enucleation of prostate: outcome and complications of self-taught learning curve. Urology 73(5):1042-1048

14. Suardi N, Gallina A, Salonia A, Briganti A, Dehò F, Zanni G, Abdollah F, Naspro R, Cestari A, Guazzoni G, Rigatti P, Montorsi F (2009) Holmium laser enucleation of the prostate and holmium laser ablation of the prostate: indications and outcome. Curr Opin Urol 19:38-43
15. Shah HN, Sodha HS, Kharodawala SJ, Khandkar AA, Hegde SS, Bansal MB (2008) Influence of prostate size on the outcome of holmium laser enucleation of the prostate. BJU Int 101(12):15361541

16. Wilson LC, Gilling PJ, Williams A, Kennett KM, Frampton CM, Westenberg AM, Fraundorfer MR (2006) A randomised trial comparing holmium laser enucleation versus transurethral resection in the treatment of prostates larger than $40 \mathrm{~g}$ : results at 2 years. Eur Urol 50(3):569-573

17. Naspro R, Suardi N, Salonia A, Scattoni V, Guazzoni G, Colombo R, Cestari A, Briganti A, Mazzoccoli B, Rigatti P, Montorsi F (2006) Holmium laser enucleation of the prostate versus open prostatectomy for prostates $>70 \mathrm{~g}$ : 24-month followup. Eur Urol 50(3):563-568

18. Mavuduru RM, Mandal AK, Singh SK, Acharya N, Agarwal M, Garg S, Kumar S (2009) Comparison of HoLEP and TURP in terms of efficacy in the early postoperative period and perioperative morbidity. Urol Int 82(2):130-135

19. Kuntz RM, Lehrich K, Ahyai SA (2008) Holmium laser enucleation of the prostate versus open prostatectomy for prostates greater than $100 \mathrm{~g}$ : 5-year follow-up results of a randomised clinical trial. Eur Urol 53(1):160-166

20. Ahyai SA, Lehrich K, Kuntz RM (2007) Holmium laser enucleation versus transurethral resection of the prostate: 3-year follow-up results of a randomized clinical trial. Eur Urol 52(5):1456-1463

21. Montorsi F, Naspro R, Salonia A, Suardi N, Briganti A, Zanoni M, Valenti S, Vavassori I, Rigatti P (2008) Holmium laser enucleation versus transurethral resection of the prostate: results from a 2-center prospective randomized trial in patients with obstructive benign prostatic hyperplasia. J Urol 179(5 Suppl):87-90

22. Gilling PJ, Aho TF, Frampton CM, King CJ, Fraundorfer MR (2008) Holmium laser enucleation of the prostate: results at 6 years. Eur Urol 53(4):744-749

23. Elzayat EA, Elhilali EM (2007) Holmium laser enucleation of the prostate (HoLEP): long-term results, reoperation rate, and possible impact of the learning curve. Eur Urol 52(5):1465-1471

24. Vavassori I, Valenti S, Naspro R, Vismara A, Dell'Acqua V, Manzetti A, Hurle R (2008) Three-year outcome following holmium laser enucleation of the prostate combined with mechanical morcellation in 330 consecutive patients. Eur Urol 53(3):599-604

25. Briganti A, Naspro R, Gallina A, Salonia A, Vavassori I, Hurle R, Scattoni E, Rigatti P, Montorsi F (2006) Impact on sexual function of holmium laser enucleation versus transurethral resection of the prostate: results of a prospective, 2-center, randomized trial. J Urol 175(5):1817-1821

26. Costello AJ, Johnson DE, Bolton DM (1992) Nd:YAG laser ablation of the prostate as a treatment for benign prostatic hypertrophy. Lasers Surg Med 12(2):121-124

27. Hoffman RM, MacDonald R, Slaton JW, Wilt TJ (2003) Laser prostatectomy versus transurethral resection for treating benign prostatic obstruction: a systematic review. J Urol 169(1):210-215

28. Wilson LC, Gilling PJ (2005) From coagulation to enucleation: the use of lasers in surgery for benign prostatic hyperplasia. Nat Clin Pract Urol 2(9):443-448

29. McAllister WJ, Gilling PJ (2004) Vaporization of the prostate. Curr Opin Urol 14(1):31-34

30. Te A (2004) The development of laser prostatectomy. BJU Int 93(3):262-265

31. Ruszat R, Seitz M, Wyler SF, Abe C, Rieken M, Reich O, Gasser TC, Bachmann A (2008) GreenLight laser vaporization of the prostate: single-center experience and long-term results after 500 procedures. Eur Urol 54(4):893-901

32. Spaliviero M, Araki M, Culkin DJ, Wong C (2009) Incidence, management, and prevention of perioperative complications of 
GreenLight HPS laser photoselective vaporization prostatectomy: experience in the first 70 patients. J Endourol 23(3):495-502

33. Choi B, Tabatabaei S, Bachmann A, Collins E, de la Rosette J, Gomez Sancha F, Muir G, Reich O, Woo H (2008) GreenLight HPS 120-W laser for benign prostatic hyperplasia: comparative complications and technical recommendations. Eur Urol Suppl 7(4):384-392

34. Horasanli K, Silay MS, Altay B, Tanriverdi O, Sarica K, Miroglu C (2008) Photoselective potassium titanyl phosphate (KTP) laser vaporization versus transurethral resection of the prostate for prostates larger than $70 \mathrm{~mL}$ : a short-term prospective randomized trial. Urology 71(2):247-251

35. Ruszat R, Wyler S, Seitz M, Lehmann K, Abe C, Bonkat G, Reich O, Gasser TC, Bachmann A (2008) Comparison of potassium-titanyl-phosphate laser vaporization of the prostate and transurethral resection of the prostate: update of a prospective non-randomized two-centre study. BJU Int 102(10):1432-1438

36. Tugcu V, Tasci AI, Sahin S, Zorluoglu F (2008) Comparison of photoselective vaporization of the prostate and transurethral resection of the prostate: a prospective nonrandomized bicenter trial with 2-year follow-up. J Endourol 22(7):1519-1525

37. Bouchier-Hayes DM, Anderson P, Van Appledorn S, Bugeja P, Costello AJ (2006) KTP laser versus transurethral resection: early results of a randomized trial. J Endourol 20(8):580-585

38. Skolarikos A, Papachristou C, Athanasiadis G, Chalikopoulos D, Deliveliotis C, Alivizatos G (2008) Eighteen-month results of a randomized prospective study comparing transurethral photoselective vaporization with transvesical open enucleation for prostatic adenomas greater than 80 cc. J Endourol 22(10):2333-2340

39. Rajbabu K, Chandrasekara SK, Barber NJ, Walsh K, Muir GH (2007) Photoselective vaporization of the prostate with the potassium-titanyl-phosphate laser in men with prostates of $>100 \mathrm{~mL}$. BJU Int 100(3):593-598

40. Woo H, Reich O, Bachmann A, Choi B, Collins E, de la Rosette J, Gomez Sancha F, Muir G, Tabatabaei S (2008) Outcome of the GreenLight HPS 120-W laser therapy in specific patient populations: those in retention, on anticoagulants, and with large prostates ( $\geq 80 \mathrm{ml}$ ). Eur Urol Suppl 7(4):378-383

41. Ruszat R, Wyler S, Forster T, Reich O, Stief CG, Gasser TC, Sulser T, Bachmann A (2007) Safety and effectiveness of photoselective vaporization of the prostate (PVP) in patients on ongoing oral anticoagulation. Eur Urol 51(4):1031-1038

42. Ruszat R, Wyler S, Seifert HH, Reich O, Forster T, Sulser T, Bachmann A (2006) Photoselective vaporization of the prostate: subgroup analysis of men with refractory urinary retention. Eur Urol 50(5):1040-1049

43. Hai M (2009) Photoselective vaporization of prostate: five-year outcomes of entire clinic patient population. Urology 73(4):807810

44. Te AE, Malloy TR, Stein BS, Ulchaker JC, Nseyo UO, Hai MA (2006) Impact of prostate-specific antigen level and prostate volume as predictors of efficacy in photoselective vaporization prostatectomy: analysis and results of an ongoing prospective multicentre study at 3 years. BJU Int 97(6):1229-1233

45. Kavoussi PK, Hermans MR (2008) Maintenance of erectile function after photoselective vaporization of the prostate for obstructive benign prostatic hyperplasia. J Sex Med 5(11):26692671

46. Paick JS, Um JM, Kim SW, Ku JH (2007) Influence of highpower potassium-titanyl-phosphate photoselective vaporization of the prostate on erectile function: a short-term follow-up study. J Sex Med 4(6):1701-1707

47. Wendt-Nordahl G, Huckele S, Honeck P, Alken P, Knoll T, Michel MS, Häcker A (2007) 980-nm diode laser: a novel laser technology for vaporization of the prostate. Eur Urol 52(6):17231728
48. Seitz M, Bayer T, Ruszat R, Tilki D, Bachmann A, Gratzke C, Schlenker B, Stief C, Sroka R, Reich O (2009) Preliminary evaluation of a novel side-fire diode laser emitting light at $940 \mathrm{~nm}$, for the potential treatment of benign prostatic hyperplasia: ex vivo and in vivo investigations. BJU Int 103(6):770-775

49. Seitz M, Ruszat R, Bayer T, Tilki D, Bachmann A, Stief C, Sroka R, Reich O (2009) Ex vivo and in vivo investigations of the novel $1,470 \mathrm{~nm}$ diode laser for potential treatment of benign prostatic enlargement. Lasers Med Sci 24(3):419-424

50. Ruszat R, Seitz M, Wyler SF, Müller G, Rieken M, Bonkat G, Gasser TC, Reich O, Bachmann A (2009) Prospective singlecentre comparison of 120-W diode-pumped solid-state highintensity system laser vaporization of the prostate and $200-\mathrm{W}$ high-intensive diode-laser ablation of the prostate for treating benign prostatic hyperplasia. BJU Int (Epub ahead of print)

51. Seitz M, Sroka R, Gratzke C, Schlenker B, Steinbrecher V, Khoder W, Tilki D, Bachmann A, Stief C, Reich O (2007) The diode laser: a novel side-firing approach for laser vaporisation of the human prostate-immediate efficacy and 1-year follow-up. Eur Urol 52(6):1717-1722

52. Leonardi R (2009) Preliminary results on selective light vaporization with the side-firing $980 \mathrm{~nm}$ diode laser in benign prostatic hyperplasia: an ejaculation sparing technique. Prostate Cancer Prostatic Dis (Epub ahead of print)

53. Rieken M, Wyler S, Müller G, Bonkat G, Gasser T, Bachmann A (2009) Laser vaporization of the prostate: intermediate-term follow-up with the $200 \mathrm{~W}$ high-intensity diode (HiDi) laser system. Eur Urol Suppl 8(4):269 Abstract 589

54. Wendt-Nordahl G, Huckele S, Honeck P, Alken P, Knoll T, Michel MS, Häcker A (2008) Systematic evaluation of a recently introduced $2-\mu \mathrm{m}$ continuous-wave thulium laser for vaporesection of the prostate. J Endourol 22(5):1041-1045

55. Bach T, Wendt-Nordahl G, Michel MS, Herrmann TR, Gross AJ (2009) Feasibility and efficacy of Thulium:YAG laser enucleation (VapoEnucleation) of the prostate. World J Urol (Epub ahead of print)

56. Bach T, Hermann TR, Haecker A, Michel MS, Gross A (2009) Thulium:yttrium-aluminium-garnet laser prostatectomy in men with refractory urinary retention. BJU Int (Epub ahead of print)

57. Bach T, Bach T, Netsch C, Haecker A, Michel MS, Herrmann TR, Gross AJ (2009) Thulium:YAG laser enucleation (VapoEnucleation) of the prostate: safety and durability during intermediate-term follow-up. World J Urol (Epub ahead of print)

58. Bach T, Hermann TR, Ganzer R, Burchardt M, Gross AJ (2007) RevoLix vaporesection of the prostate: initial results of 54 patients with a 1-year follow-up. World J Urol 25(3):257-262

59. Xia SJ, Zhuo J, Sun XW, Han BM, Shao Y, Zhang YN (2008) Thulium laser versus standard transurethral resection of the prostate: a randomized prospective trial. Eur Urol 53(2):382-389

60. Reich O, Gratzke C, Bachmann A, Seitz M, Schlenker B, Hermanek P, Lack N, Stief CG (2008) Urology Section of the Bavarian Working Group for Quality Assurance, Morbidity, mortality and early outcome of transurethral resection of the prostate: a prospective multicenter evaluation of 10,654 patients. J Urol 180(1):246-249

61. Gratzke C, Schlenker B, Seitz M, Karl A, Hermanek P, Lack N, Stief CG, Reich O (2007) Complications and early postoperative outcome after open prostatectomy in patients with benign prostatic enlargement: results of a prospective multicenter study. J Urol 177(4):1419-1422

62. Madersbacher S, Lackner J, Brössner C, Röhlich M, Stancik I, Willinger M, Schatzl G (2005) Prostate Study Group of the Austrian Society of Urology, Reoperation, myocardial infarction and mortality after transurethral and open prostatectomy: a nationwide, long-term analysis of 23,123 cases. Eur Urol 47(4):499-504 